Supporting Information

\title{
An Environmentally Friendly Three-Dimensional Printed Graphene- Integrated Polylactic Acid Electrochemical Sensor for the Quality Control of Biofuels
}

Afonso F. João $\uparrow, \ddagger$, Tiago A. Matias $\uparrow$, Jéssica S. Gomes $\uparrow$, Robson R. Guimaraes $\S$, Raquel M. F. Sousa† and Rodrigo A. A. Muñoz $\dagger^{*}$

† Institute of Chemistry, Federal University of Uberlândia, 38400-902, Uberlândia, Minas Gerais, Brazil.

* Department of Mathematics and Natural Science, Púnguè University, Chimoio, Manica, Mozambique

$\S$ Department of Fundamental Chemistry, Institute of Chemistry, University of Sao Paulo, Av. Prof. Lineu Prestes 748, Butantã, São Paulo, SP, 05508-000, Brazil.

*Corresponding author:

munoz@ufu.br

Number of pages: 8

Number of figures: 10

Number of tables: 1 


\section{Instrumentation}

The Raman spectra of the 3D-printed electrodes were obtained on a Horiba Confocal LabRAM HR Evolution microscope employing a laser at $\lambda=532 \mathrm{~nm}$ with around $2 \mathrm{~mW}$. The attenuated total reflectance infrared (ATR-FTIR) spectroscopy was performed using a PerkinElmer Frontier spectrometer equipped with a diamond crystal plate.

The volume size distribution histograms were obtained using the Dynamic Light Scattering (DLS) technique through a Malvern Zetasizer Nano ZS particle size analyzers equipped with a He-Ne laser $(633 \mathrm{~nm})$ light source. The biodiesel emulsions in water were placed in $4 \mathrm{~mL}$ volume quartz cuvette with a $10 \mathrm{~mm}$ optical path and the measurement parameters were $0.3 \mathrm{~nm}-10.0 \mu \mathrm{m}$ (diameter) measurement range, 1.445 material refractive index, 25 degrees Celsius room temperature and $173^{\circ}$ backscatter detection angle.

High-performance liquid-chromatography (HPLC) was performed in a Shimadzu SPD-M10Avp chromatograph employing a diode-array detector and reversed phase analytical column Shim-pack CLC-ODS(M) ${ }^{\circledR}$ C18 (4.6 mm internal diameter with $15 \mathrm{~cm}$ in length) from Shimadzu. The mobile phase was composed of acetonitrile and water (pH $\left.2.1, \mathrm{H}_{3} \mathrm{PO}_{4}\right)(75: 25, \mathrm{v} / \mathrm{v})$, and a flow rate of $1.0 \mathrm{~mL} \mathrm{~min}^{-1}$. The detection was performed in the range between 200 and $600 \mathrm{~nm}$, while the value of $299 \mathrm{~nm}$ was fixed for sample analyses. The retention time was 3.5 min for the elution of TBHQ. The aliquots of $20 \mu \mathrm{L}$ of standard TBHQ or biodiesel solutions were direct diluted in the mobile phase before the injection. 

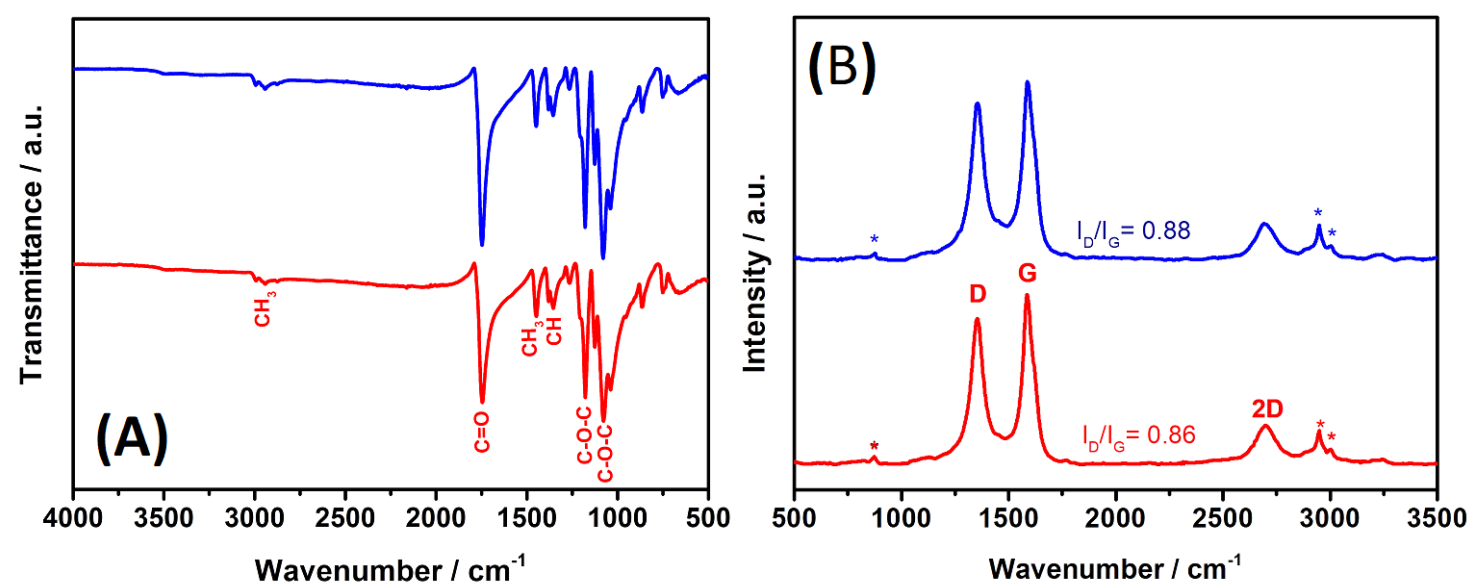

Fig. S1. FTIR (A) and Raman spectra (B) of 3D-printed electrodes before (blue lines) and after (red lines) electrochemical treatment. The marked bands at Raman spectra are assigned to the PLA polymer.
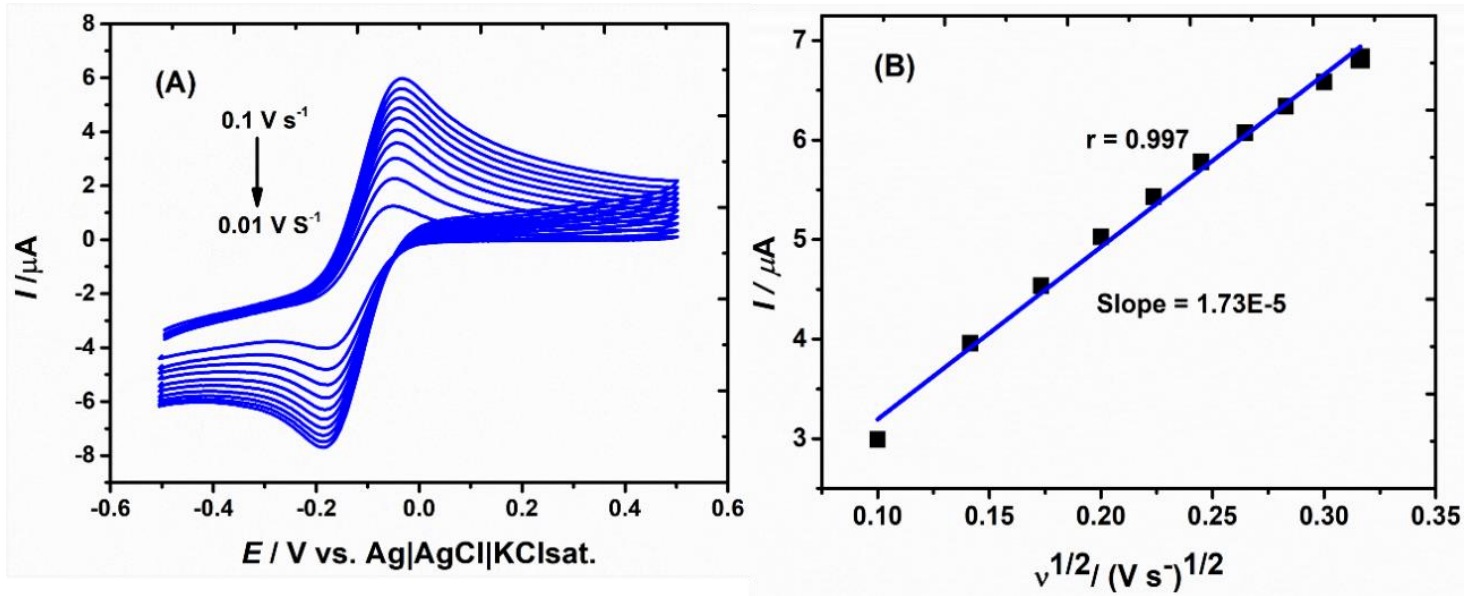

Fig. S2. Study of the scan rate: (A) Cyclic voltammograms obtained for the redox process of $1.0 \mathrm{mM}\left[\mathrm{Ru}\left(\mathrm{NH}_{3}\right)_{6}\right]^{2+/ 3+}$ in $0.1 \mathrm{M}$ of $\mathrm{KCl}$ at the G/PLA electrode in different scan rates (0.01 to $\left.0.1 \mathrm{~V} \mathrm{~s}^{-1}\right)$ and (B) plots of current response as function of square root of the scan rate. 

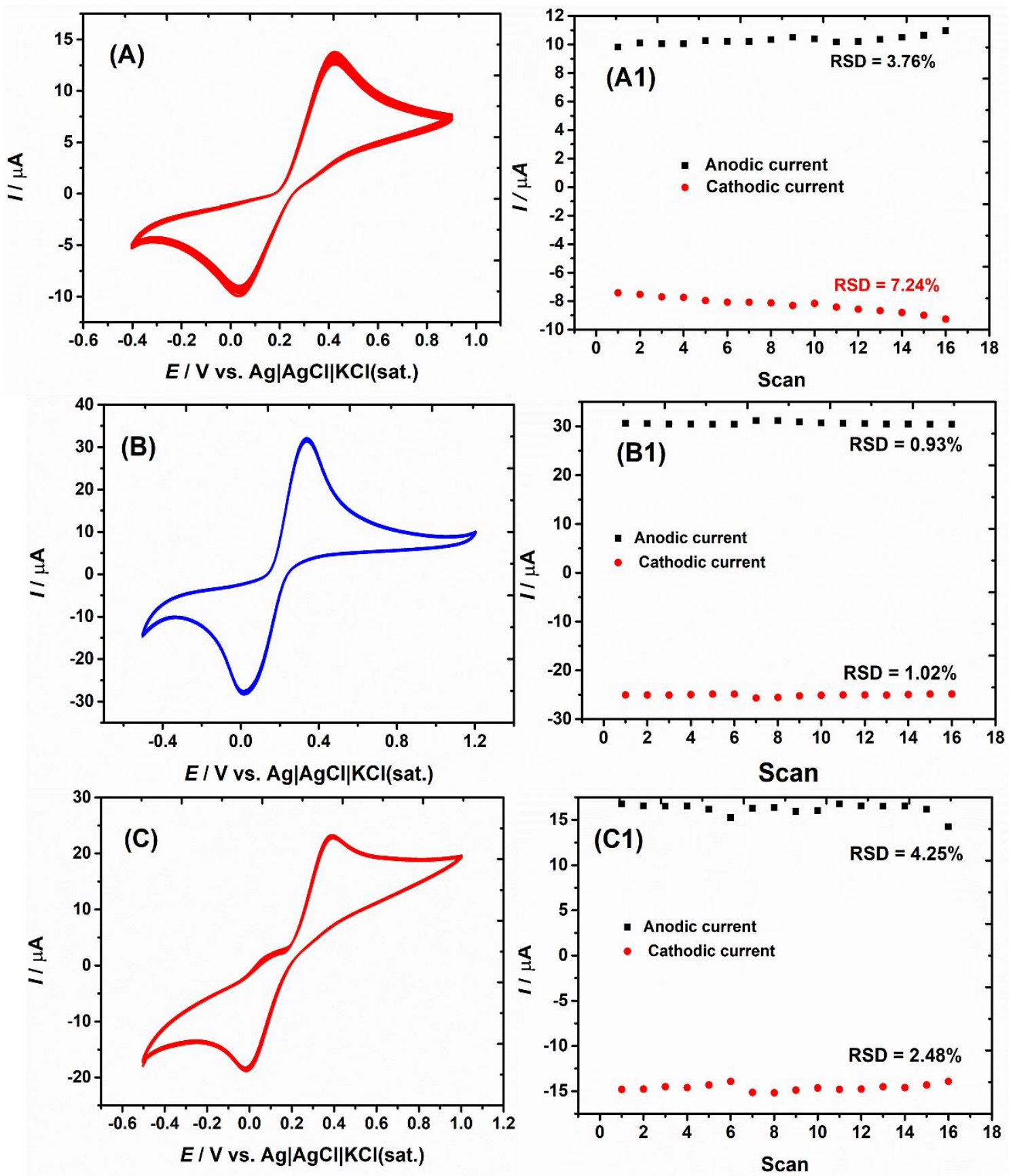

Fig. S3. Cyclic voltammetry for $1.0 \mathrm{mM}$ TBHQ on 3D printed G/PLA electrodes fabricated with different layer thickness of conductive filament: (A) 5.5, (B) 3.5 and (C) $1.5 \mathrm{~mm}$. Plots of anodic and cathodic peaks current for consecutive scans $(\mathrm{n}=16)$ are presented in $\mathrm{A} 1, \mathrm{~B} 1$ and $\mathrm{C} 1$, respectively. Conditions: scan rate $50 \mathrm{mV} \mathrm{s}^{-1}$ and step potential $5 \mathrm{mV}$. 
Table S1. Colloid size distribution (by volume) for biodiesel-water emulsion samples in presence of $20 \mu \mathrm{mol} \mathrm{L}{ }^{-1}$ de TBHQ and $40 \mu \mathrm{mol} \mathrm{L} \mathrm{L}^{-1}$ of the surfactants.

\begin{tabular}{|c|c|c|c|c|c|c|}
\hline \multirow{2}{*}{ Sample } & \multicolumn{2}{|c|}{ SDS } & \multicolumn{2}{c|}{ Triton X-100 } & \multicolumn{2}{c|}{ CTAB } \\
\cline { 2 - 7 } & $\begin{array}{c}\text { Z-Average } \\
\text { (d.nm) }\end{array}$ & PdI & $\begin{array}{c}\text { Z-Average } \\
\text { (d.nm) }\end{array}$ & PdI & $\begin{array}{c}\text { Z-Average } \\
(\text { d.nm })\end{array}$ & PdI \\
\hline Biodiesel & 736.1 & 0.591 & 978.2 & 0.663 & 661.9 & 0.411 \\
\hline Biokerosene & 609.8 & 0.644 & 1234 & 0.281 & 1249 & 0.418 \\
\hline
\end{tabular}
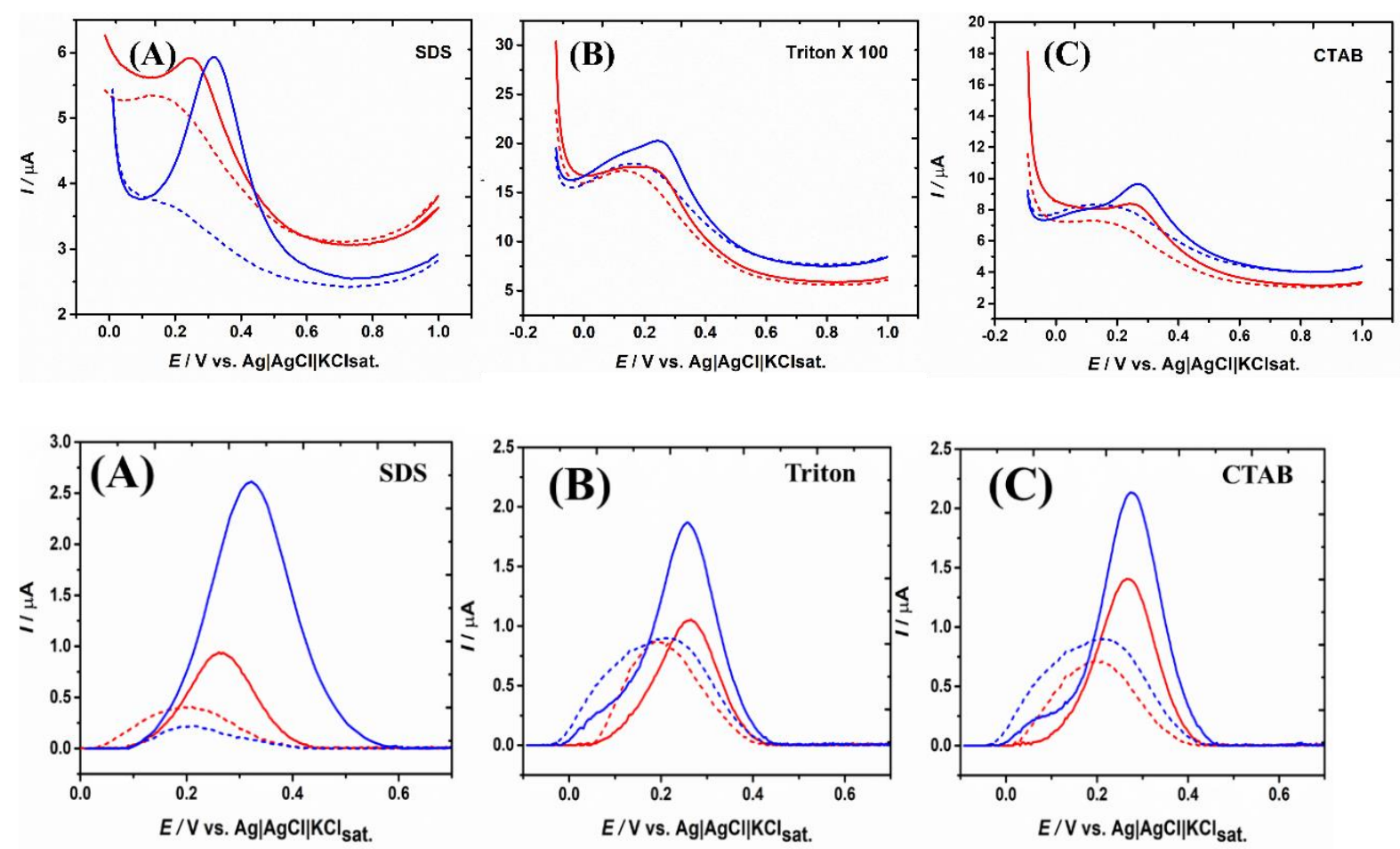

Figure S4. Original (upper plots) and respective baseline corrected SWVs (lower plots) obtained for $20 \mu \mathrm{mol} \mathrm{L}{ }^{-1}$ TBHQ in the presence of $40 \mu \mathrm{mol} \mathrm{L} \mathrm{L}^{-1}$ of the surfactants SDS (A), Triton X-100 (B), CTAB (C) in $0.12 \mathrm{~mol} \mathrm{~L}^{-1} \mathrm{BR}$ buffer at $\mathrm{pH} 4.05$ without the application of potential pulse (red solid lines for TBHQ responses and red dashed lines for blanks) and with the potential application of $-0.7 \mathrm{~V}$ for $1 \mathrm{~s}$ before the SWV scan (blue solid lines for TBHQ responses and blue dashed lines for blanks). SWV conditions: potential of amplitude $($ Esw $)=30 \mathrm{mV}$; frequency $(f)=20 \mathrm{~Hz}$; step potential $(\Delta$ Es $)=10$ $\mathrm{mV}$. 

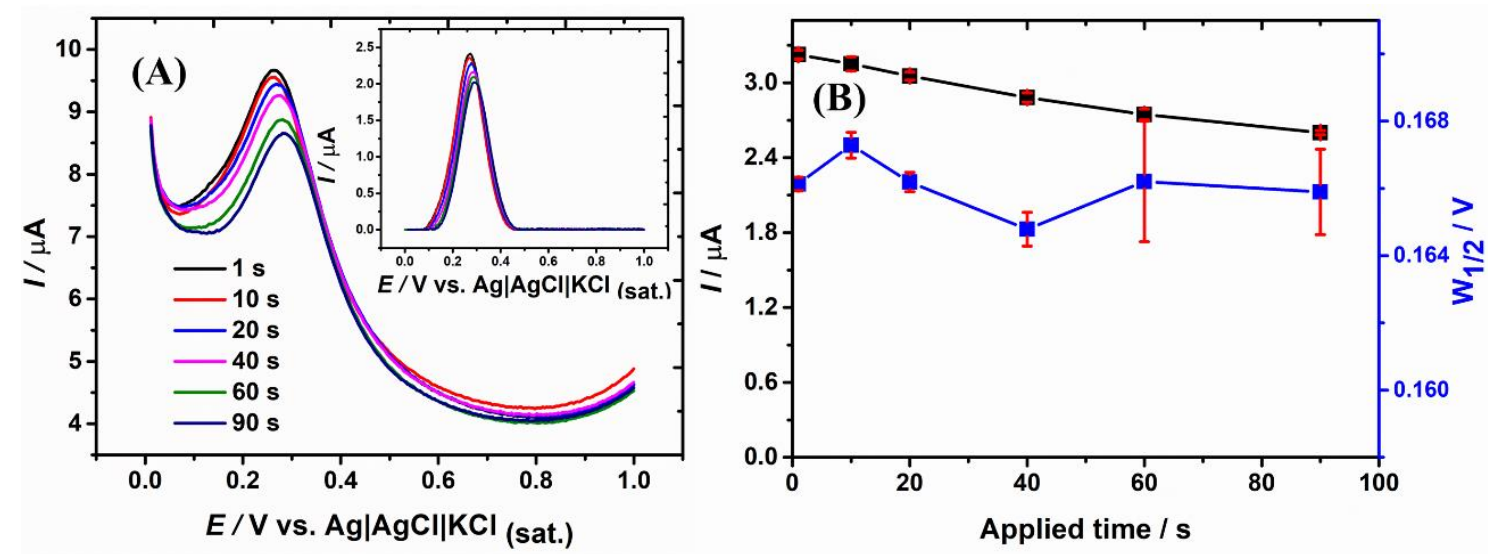

Fig. S5. (A) SWVs (baseline corrected scans are inset) for $20 \mu \mathrm{mol} \mathrm{L} \mathrm{L}^{-1} \mathrm{TBHQ}$ in $\mathrm{BR}$ buffer ( $\mathrm{pH} 4.05$ ) in the presence of $40 \mu \mathrm{mol} \mathrm{L}^{-1}$ of SDS as function of the time of the applied potential (fixed at $-0.7 \mathrm{~V}$ ); (B) $I$ and $\mathrm{W}_{1 / 2}$ obtained from peak currents as function of time. SWV conditions: Amplitude $($ Esw $)=30 \mathrm{mV}$; frequency $(f)=20 \mathrm{~Hz}$; step potential $(\Delta \mathrm{Es})=10 \mathrm{mV}$; stirring rate $($ during pretreatment $)=1000 \mathrm{rpm}$.
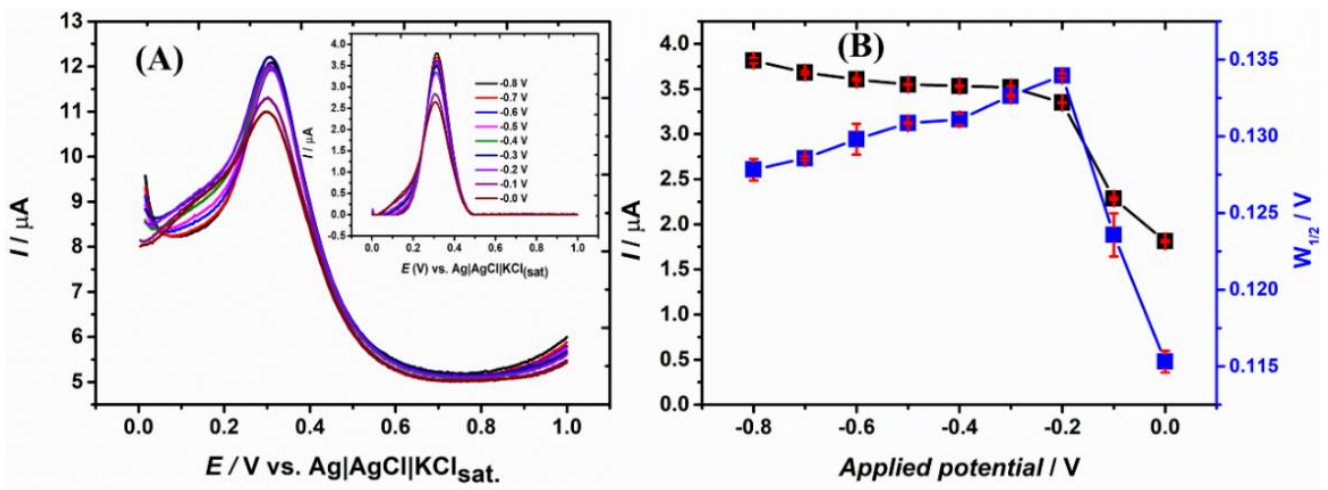

Fig. S6. SWVs (baseline corrected scans are inset) for $20 \mu \mathrm{mol} \mathrm{L} \mathrm{L}^{-1} \mathrm{TBHQ}$ in BR buffer (pH 4.05) in the presence of $40 \mu \mathrm{mol} \mathrm{L}^{-1}$ of SDS as function of the applied potential (time fixed at $1 \mathrm{~s}$ ). (B) $I$ and $\mathrm{W}_{1 / 2}$ obtained from peak currents as function of applied potential. SWV conditions: Amplitude $(\mathrm{Esw})=30 \mathrm{mV}$; frequency $(f)=20 \mathrm{~Hz}$; step potential $(\Delta \mathrm{Es})$ $=10 \mathrm{mV}$. 

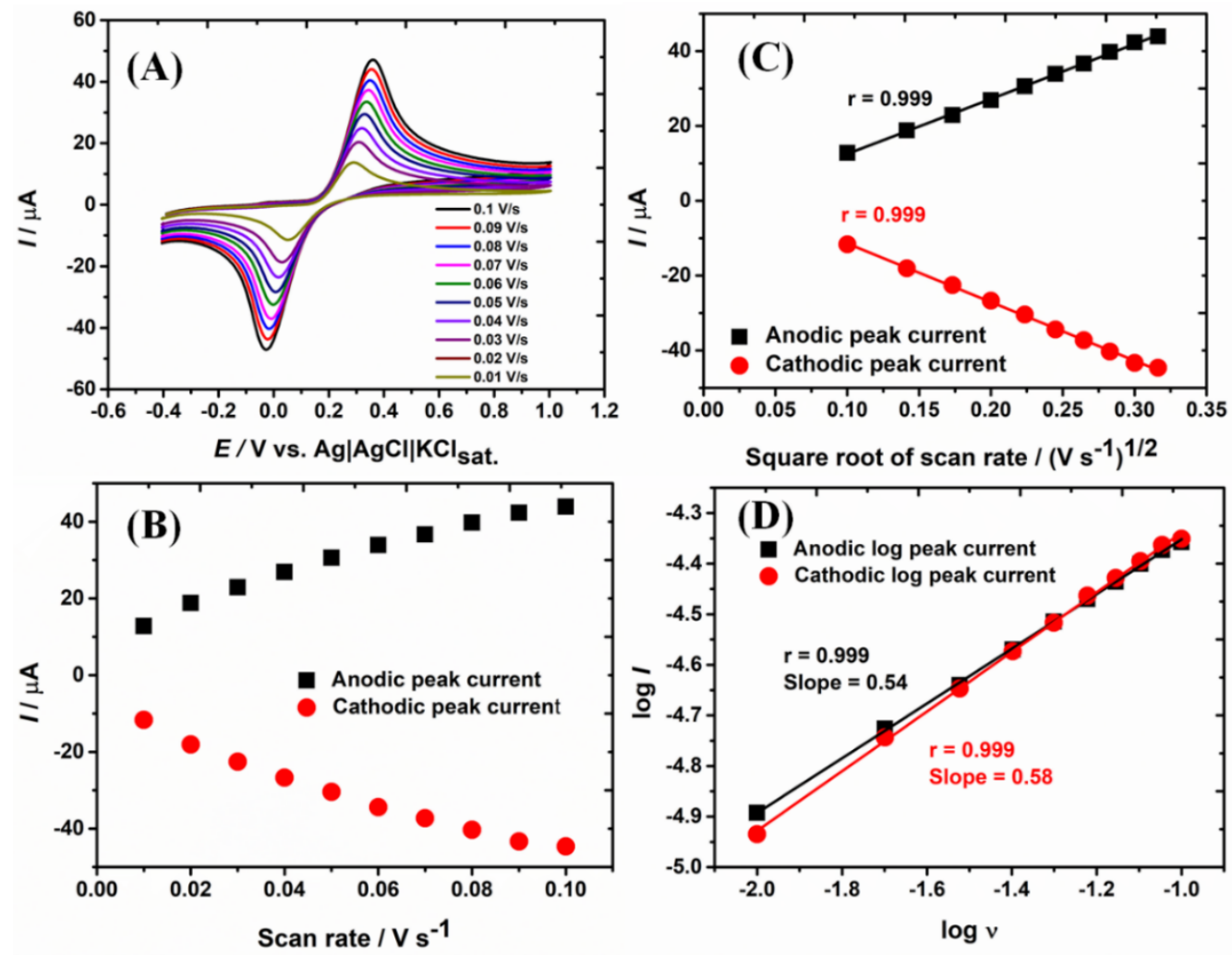

Fig. S7. Study of the scan rate: (A) Cyclic voltammograms obtained for the oxidation of $1.0 \mathrm{mmol} \mathrm{L}-1$ TBHQ and $40.0 \mu \mathrm{mol} \mathrm{L}{ }^{-1} \mathrm{SDS}$ in $0.12 \mathrm{~mol} \mathrm{~L}^{-1} \mathrm{BR}$ buffer solution $(\mathrm{pH}=$ $4.05)$ at the G/PLA electrode in different scan rates $\left(0.02\right.$ to $\left.0.1 \mathrm{~V} \mathrm{~s}^{-1}\right)$ and plots of current response in function of: (B) scan rate, (C) square root of the scan rate and (D) $\log I$ vs. $\log v$.
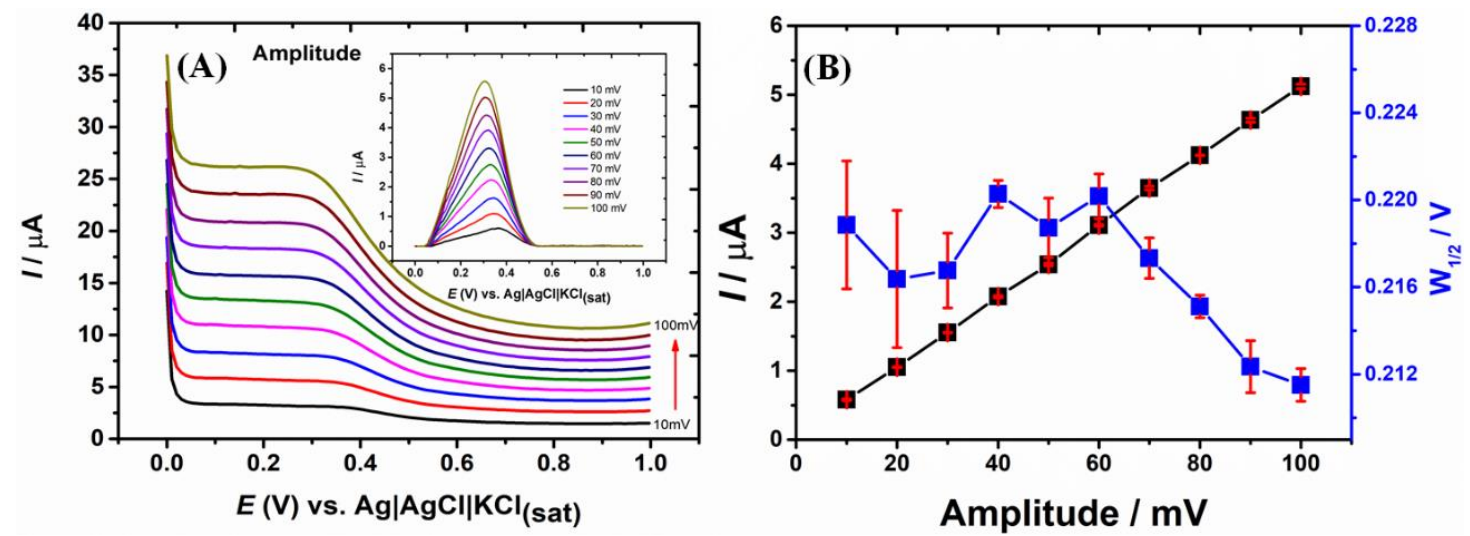

Fig. S8. SWVs (baseline corrected scans are inset) for the study of potential of amplitude (ESw) as function of SWV peak current for $20 \mu \mathrm{mol} \mathrm{L}^{-1}$ TBHQ in $0.12 \mathrm{~mol} \mathrm{~L}^{-1} \mathrm{BR}$ buffer solution $(\mathrm{pH}=4.05)$. Applied potential of $-0.7 \mathrm{~V}$ for $1 \mathrm{~s}$; SWV conditions: step potential $\left(\Delta \mathrm{E}_{\mathrm{s}}\right): 10 \mathrm{mV}$; frequency $(f): 20 \mathrm{~s}^{-1}$. 

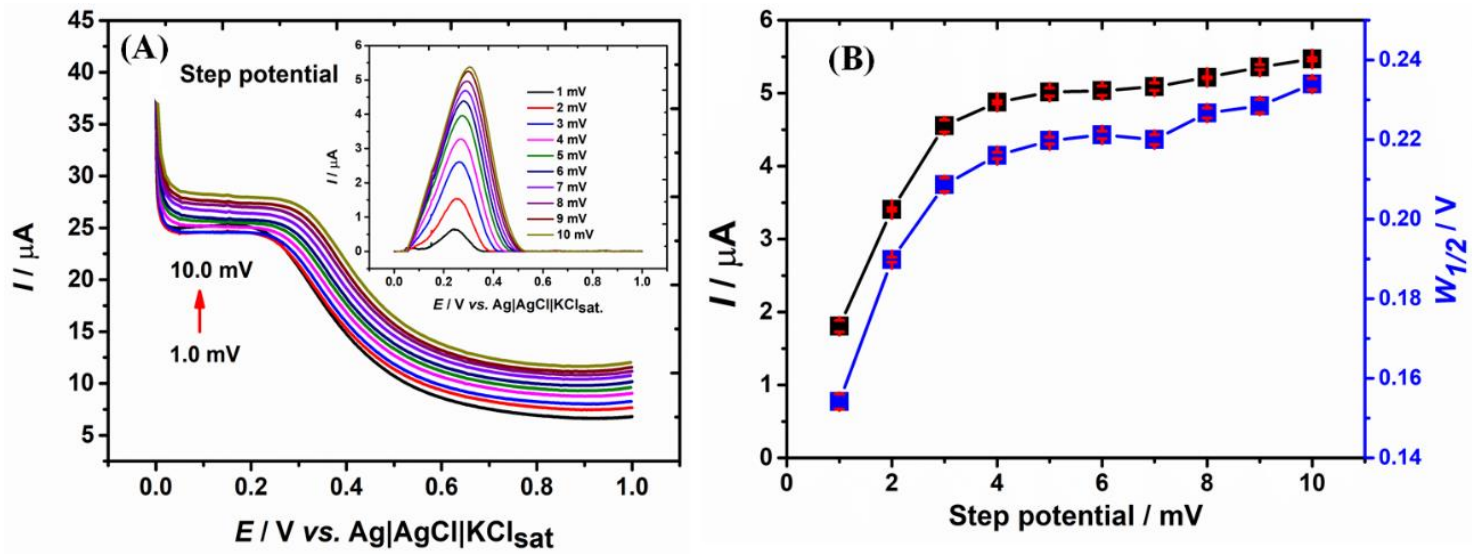

Fig. S9. SWVs (baseline corrected scans are inset) for the step potential $\left(\Delta \mathrm{E}_{\mathrm{s}}\right)$ as function of SWV peak current for $20 \mu \mathrm{mol} \mathrm{L} \mathrm{L}^{-1}$ TBHQ in $0.12 \mathrm{~mol} \mathrm{~L}^{-1} \mathrm{BR}$ buffer solution ( $\mathrm{pH}=$ 4.05). Applied potential of $-0.7 \mathrm{~V}$ for $1 \mathrm{~s}$; SWV conditions: Amplitude: $80 \mathrm{mV}$; frequency $(f): 20 \mathrm{~s}^{-1}$.
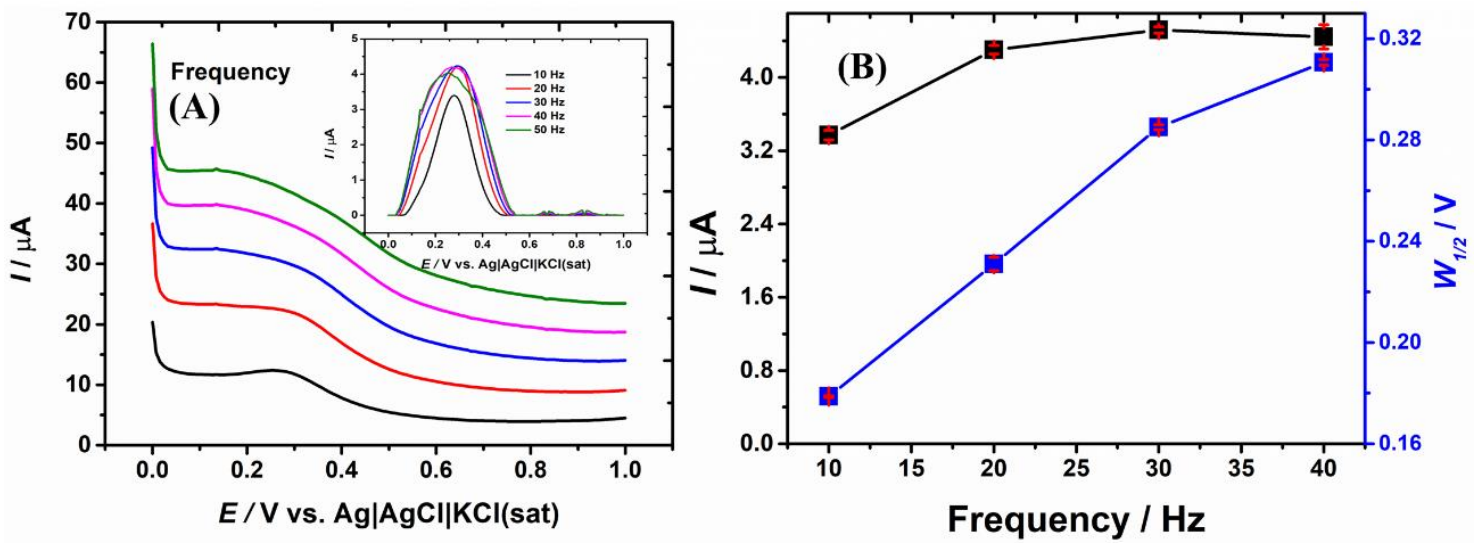

Fig. S10. SWVs (baseline corrected scans are inset) for the study of frequency $(f)$ as function of SWV peak current for $20 \mu \mathrm{mol} \mathrm{L}{ }^{-1}$ TBHQ in $0.12 \mathrm{~mol} \mathrm{~L}^{-1} \mathrm{BR}$ buffer solution $(\mathrm{pH}=4.05)$. Applied potential of $-0.7 \mathrm{~V}$ for $1 \mathrm{~s}$; SWV conditions: Amplitude: $80 \mathrm{mV}$; step potential: $4 \mathrm{mV}$. 